\title{
ABOUT FORM LIBIT AND METHODS DETERMINATION PARAMETER WIND THREADS OF THE BASE ON LIBIT-WARPING DRUM
}

\author{
${ }^{1}$ Siddikov Patkhillo Siddikovich, \\ ${ }^{1}$ Professor, Tashkent institute textile and light industry, Uzbekistan. \\ ${ }^{2}$ Umarova Munavvar Omonbekovna \\ ${ }^{2}$ Senior teacher, Fergana Polytechnic Institute, Uzbekistan.
}

Article DOI: https://doi.org/10.36713/epra2337

\begin{abstract}
Considered determination form wind of the threads libit on libit-thread base drum and thickness of rolling with consideration of the machine construction and forms of thread rolls of libits. Samples are provided for determining the scope and thickness of libit rolls.
\end{abstract}

KEYWORDS: fabric, avrov fabric, avrband, libit, libit reels, roll layers, libit thread base, libit wrapping roll, cylindrical roll, breaking of roll-reels, segment, sector, libit scope.

\section{INTRODUCTION}

In the Fergana valley made traditional atlas silk - the national fabric of Uzbekistan. Most atlas silks were made on machines, but in Margilan they had retained the traditional approach, making their workshop a mecca for textile enthusiasts. I visited his workshop a couple of months later and watched the complicated process of dyeing atlas silk using ikat dyeing, in which warp threads are bound according to a pattern and then immersed in dye-baths, building up a colour pattern through resist-dyeing, a kind of tiedyeing. The reassembled warp threads are then woven with just one weft colour, creating a vertical blur of colours subtly bleeding into each other. A young weaver in love is credited with the invention of atlas silk. The object of his affections was the daughter of a wealthy landowner who showed no interest in the humble weaver. His only hope, she told him, was to dazzle her with the most beautiful fabric ever created. The besotted weaver set to work, but nothing he produced received more than a scornful glance. Finally - his hands worn to shreds - he gave up. Dejected, he went to a stream that ran near his workshop, dipping his bleeding hands in the waters. Blood-red blended with the shimmering yellow of the reflected sun and dashes of green from the overhanging trees and the patches of blue sky. Inspired, he rushed back to his loom and wove atlas silk. His shallow sweetheart fell passionately and predictably in love with both the design and the designer."

History of Khan-Atlas tells that a long time ago one of the rulers of Margilan who had four wives decided to marry for the fifth time. His choice fell on the young daughter of a poor weaver. Being annoyed, the girl's father fell on his knees before the old khan, asking him to withdraw from the girl. The khan replied that he would full fill the request of a poor man if the next morning he created something extraordinary that would make the Khan forget about the beauty of the girl. The sad weaver sat on the bank of the channel, not knowing what to do next. And suddenly he saw the reflection of clouds in the water, which were painted with a rainbow of colours after the last rain. "Oh, heavens, thank you for the idea!" He cried and ran home to get to work immediately.

\section{OBJECTIVES}

The next morning he wove an unusual cloth: light and airy as a cloud, cool like pure mountain air and as iridescent as a rainbow. When the master brought this extraordinary fabric to the khan, he was

$$
\text { (6) } 2020 \text { EPRA IJRD | Journal DOI: https://doi.org/10.36713/epra2016 | www.eprajournals.com |100 | }
$$


shocked with its enchanting beauty, "How did you do that?" - He asked the weaver. And the weaver said: "I took green rain-washed leaves, added colours of tulip petals, the blush of dawn, blue night sky, patches of sunlight on the water and bright eyes of my beloved daughter and mixed everything up." The unusual fabric was called Khan-Atlas ("Khan silk"), and the khan married the weaver's daughter to his beloved son.

Bukhara, Margilan, Namangan, Kokand were and are the centers of Uzbekistan decorative weaving crafts. Today these workshops are renowned for the beauty of hand-made silk fabrics all over the world. Centuries-old traditions of hand-woven silk and cotton fabrics have been an essential part of national clothes, culture, and interior.

\section{METHODOLOGY}

It is worth to say about ancient traditions of hand-made silk fabrics, which are called the Ikat on the West. This name came from Indonesia and originated from the verb "mengikat", which means "to bundle". It is a very ancient way of creating designs in fabric by resist-dyeing the threads before the fabric is woven. In Uzbekistan, such a technique is called the abrband, which in Persian means "tying a cloud", and the fabrics produced by such a method are called "abra" fabrics.

\section{SAMPLING DESIGN}

There are some legends about the origin of such a technique. One legend states that once an artist sat by a fast-running stream. The stream reflected the clouds and changed their form. Suddenly sunrays were fractured and became a rainbow which was reflected in the stream. The artist saw a picture of clouds playing with colours. He painted that picture and showed it to weavers who then transferred his picture to fabrics. Later the word abr (which means cloud) was used as the name of the process of dyeing base threads in traditional fabrics, so fabrics were named abr-fabrics and weavers were called abrbands.

Uzbekistan silk fabrics had their own names: shoi, khan-atlas, atlas, podshokhi. These types of fabrics were produced from pure silk. The fabrics made of cotton weft and silk warp was called adras, bekasam, pasma, banoras.

Ikat patterns were noted by its diversity; each school of silk weaving differed by their local artistic peculiarities. Patterns were named after shapes they resembled. The most wide-spread ornaments were "tumorcha" - amulet, "tarok" - comb, "gadjak" - jewelry, "bodom" - almond, "darakht" - tree, "anor" - pomegranate, "Oy" - the Moon, "shokh" horn, "chirog" - lampad, "ilon izi" - snake trail, "kapalak" - butterfly, "chayon" - scorpion, and etc.

Modern ikats also were made in the shape of traditional Uzbek jewellery including drop-earrings and triangular-shaped pendants (tumor). When a young Uzbek woman got married, she was expected to wear jewellery, which represented the wealth of her family. It was said that if a woman could not walk due to the heaviness of her new jewellery she came from a wealthy family. However, jewellery was expensive, and a wedding ceremony without jewellry was considered shameful, so to solve this problem, people began to buy ikats with patterns representing jewellery.

Libit is used to weave our national silk "Khonatlas","Adras", and "Bekasam".Libit-is are some ribbons, which can be wrapped to one roll in one time together. There are 80 ribbons in a libit. Avrov fabic is widely used for sewing dresses, suits in different sizes, for different nations such as Uzbek, Tadjik etc. Avrov fabric is important in foreign countries, too. The main distinctive peculiarity in technics of manufacture avrov fabric is that the ribbons are painted till weaving way. It's differ than painting national silk. Avrov fabric is a fabric, which rolls are pointed till the process weaving in avrov way. Successiveness (methods) and technology of painting rolls depend quantities of colors demonstrated in the picture, which is seen on fabric (stuff).

$$
\kappa_{\text {ye.ock: }}=\kappa_{\text {ye. }}-1 .
$$

Note: $\kappa_{\text {ye.ock. }}$-means number of rolls which will be painted.

1-means rolls which will be painted in white.

It's need natural colors to paint rolls.

Here is instruction of how to get colors:

Yellow-skin of pomegranate,

Reed-painting from koship, which is taken from dried insects, brown-skins of Greek nuts? (natural silk)

Roll itself is also taken from natural things

Here is an example of avrov fabric "Khonatlas" in a picture 1 
SJIF Impact Factor: 6.260| ISI I.F.Value:1.241| Journal DOI: 10.36713/epra2016

ISSN: 2455-7838(Online)

EPRA International Journal of Research and Development (IJRD)

Volume: 5 | Issue: 3 | March 2020

- Peer Reviewed Journal

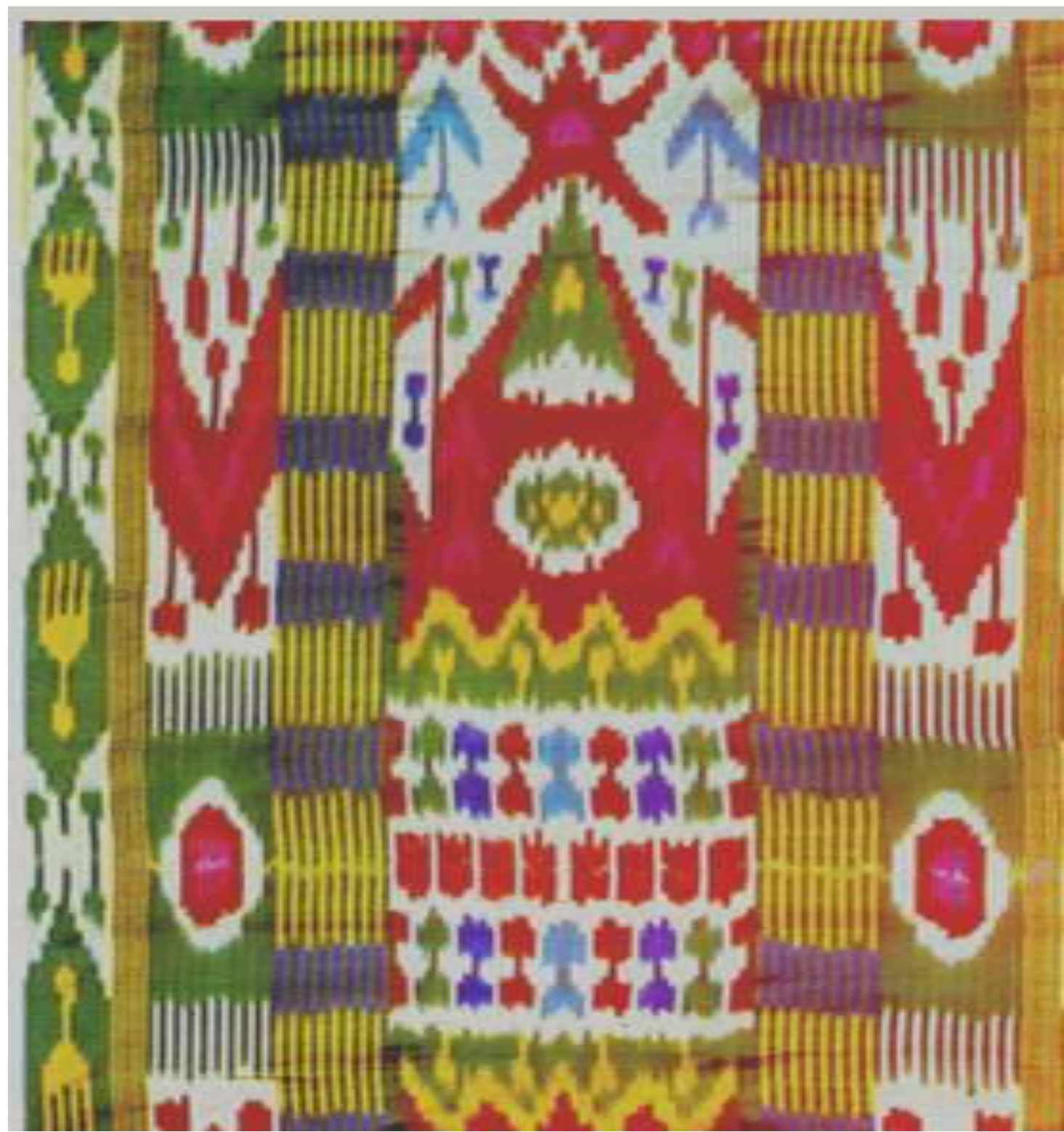

Picture 1: Avrov fabric (Khan Atlas)

The rolls are wrapping based roll as oval shape as in picture 2(a)

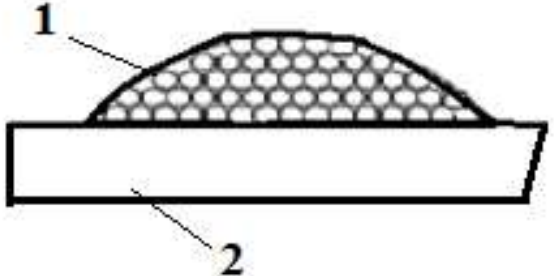

a)

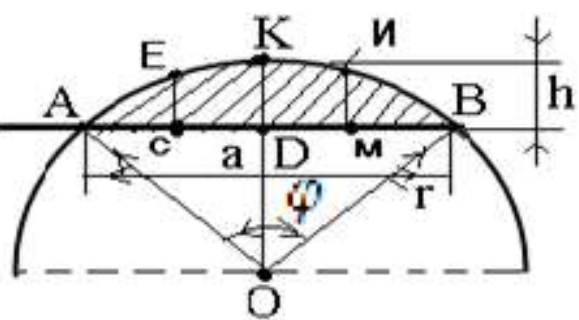

б)

Picture 2: a) Scheme of libit 1, which is wrapped into libit-wrapping machine.

b) Scheme of selecting form of wrapping libits.

2020 EPRA IJRD | Journal DOI: https://doi.org/10.36713/epra2016 | www.eprajournals.com |102 | 


\section{EPRA International Journal of Research and Development (IJRD)}

Volume: 5 | Issue: 3 | March 2020

- Peer Reviewed Journal

One must do several times of experiments that to get libit and to wrap into libit based roll. The length of roll is 300 meters (inch). Measurement of the roll is carried out by cron (a type of instrument, which weights till $0.01 \mathrm{~mm})[2, \mathrm{p} 109]$.

Let's see how to measure rolls. There are 3 commas in a wrapping machine.

\section{№ Experiment}

\begin{tabular}{|c|r|}
\hline No Experiment & AD \\
\cline { 2 - 2 } & 14,8 \\
\hline 1 & 15,0 \\
\hline 2 & 15,0 \\
\hline 3 & 14,78 \\
\hline 4 & 15,0 \\
\hline 5 & 14,8 \\
\hline 6 & 14,9 \\
\hline 7 & 15,0 \\
\hline 8 & 14,90 \\
\hline 9 & 15,0 \\
\hline 10 & 149,40 \\
\hline Total & 14,94 \\
\hline $\bar{X}$ & \\
\hline
\end{tabular}

This is A.G.Sevostyanova's method in statistical manufacture [3,p 26-28]. Here X shows a general run of the experiment.

\section{RESULTS}

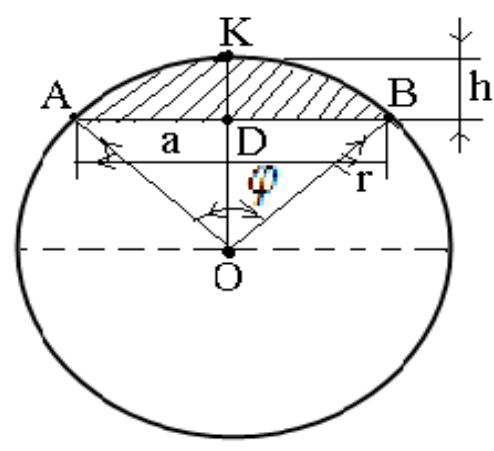

Picture 3. Scheme of profile of libit, which is wrapped in a form of the segment.

A flat area of segment AKBA is choosen in a form:

$$
\mathrm{S}=\frac{2}{3} \mathrm{ah}+\frac{\mathrm{h}^{3}}{2 a},
$$

"a" is a length of the link, " $h$ " is a height of segment wrapping, " 2 " on the right side is not so necessary, you needn't take into consideration it. [4,p 60-67].

Flat area of secsion OAKBO is as follows:

$$
\mathrm{S}_{\mathrm{OAKBO}}=\mathrm{S}_{1}=\mathrm{r}^{2} * \frac{\pi}{360} * \varphi^{0}
$$

" $r$ " is a radius of segment ' $\varphi^{0}$, is a central corner, " $\ell$ " is a length of arch, which is formulated: $\ell=\frac{\pi}{180}$

Then we'll select flat area of triangle OAB:

$$
\begin{array}{rl}
\mathrm{S}_{\mathrm{OAB}}=\mathrm{S}_{2}=\frac{1}{2} * \mathrm{DB} & * \mathrm{OB}=\frac{r * \operatorname{Sin} \frac{\varphi}{2} * \mathrm{r} * \operatorname{Cos} \frac{\varphi}{2}}{2}=\frac{\mathrm{r}^{2} * 2 * \operatorname{Sin} \frac{\varphi}{2} * \mathrm{r} * \operatorname{Cos} \frac{\varphi}{2}}{4}= \\
\text { 2020 EPRA IJRD | Journal DOI: https://doi.org/10.36713/epra2016 |www.eprajournals.com |103 | }
\end{array}
$$


$=\frac{r^{2}}{4} * \operatorname{Sin} \varphi$.

According $S_{1} \& S_{2}$ we'll find out the flat area of segment:

$$
\begin{aligned}
\mathrm{S}_{\text {cer. }} & =\mathrm{S}_{1}-\mathrm{S}_{2}=\frac{\mathrm{r}^{2} * \pi * \varphi^{0}}{360}-\frac{\mathrm{r}^{2}}{360} * \operatorname{Sin} \varphi^{0}=\mathrm{r}^{2}\left(\frac{\pi}{360} * \varphi^{0}-\frac{\operatorname{Sin} \varphi^{0}}{4}\right)= \\
& =\frac{\mathrm{r}^{2}}{4}\left(\frac{\pi}{90} * \varphi^{0}-\operatorname{Sin} \varphi^{0}\right) .
\end{aligned}
$$

Let's denominate the length of arch AKB segment:

$$
\mathrm{AKB}=\ell=\frac{\pi r}{180} * \varphi^{0} \text {. }
$$

Height of segment (height of profile roll of libits) KD

$\mathrm{KD}=\mathrm{h}=\mathrm{r}-\mathrm{r} \operatorname{Cos} \frac{\varphi}{2}$ отсюда $\mathrm{h}=\mathrm{r}\left(1-\operatorname{Cos} \frac{\varphi}{2}\right)$.

Now we'll find quantity of arch BD

$\mathrm{BD}=\frac{a}{2}=\mathrm{r} * \operatorname{Sin} \frac{\varphi}{2}$,

General length of arch is

$$
\mathrm{a}=2 * \mathrm{r} * \operatorname{Sin} \frac{\varphi}{2} \text {. }
$$

For example: $\varphi=90^{\circ}$, than $\frac{\varphi}{2}=45^{\circ}$.

Denominate height of segment:

$\mathrm{h}=\mathrm{r}\left(1-\cos \frac{\varphi}{2}\right)=\mathrm{r}\left(1-\cos 45^{\circ}\right)=\mathrm{r}\left(1-\frac{\sqrt{2}}{2}\right)=\mathrm{r}-\mathrm{r} \frac{\sqrt{2}}{2}$,

The length of arch of segment is:

$\mathrm{a}=2 \mathrm{r} * \sin \frac{\varphi}{2}=2 * \mathrm{r} \sin 45^{\circ}=2 * \mathrm{r} * \frac{\sqrt{2}}{2}=\mathrm{r} * \sqrt{2}$, than $\mathrm{r}=\frac{a * \sqrt{2}}{\sqrt{2} * \sqrt{2}}=\frac{a * \sqrt{2}}{2}$

Characteristic curve between length $\&$ height of arch is:

$\mathrm{h}=\mathrm{r}-\mathrm{r} \frac{\sqrt{2}}{2}$,

Length of arch is: $a=r * \sqrt{2}$.

Formula (12) $\mathrm{r}=\frac{a}{\sqrt{2}}$, we'll get from formula (9)

$$
\begin{aligned}
& \mathrm{h}=\frac{a}{\sqrt{2}}-\frac{a}{2}=\frac{a * \sqrt{2}}{\sqrt{2} * \sqrt{2}}-\frac{a}{2}=\frac{a * \sqrt{2}}{2}-\frac{a}{2}=\frac{a}{2}(\sqrt{2}-1) \\
& \text { or } \quad \mathrm{h}=\frac{a}{2}(1,4-1)=\frac{a}{2} * 0,4=0,2 * \mathrm{a} .
\end{aligned}
$$

We've got characteristic curve between length $\&$ height of arch. 


\title{
EPRA International Journal of Research and Development (IJRD)
}

Volume: 5 | Issue: 3 | March 2020

\author{
- Peer Reviewed Journal
}

Now, we'll denominate flat area of libit in a cylindrical part, taking into consideration perimeter of roll. This scheme of roll of libit as a cylindrical shape you can see in picture 5 .

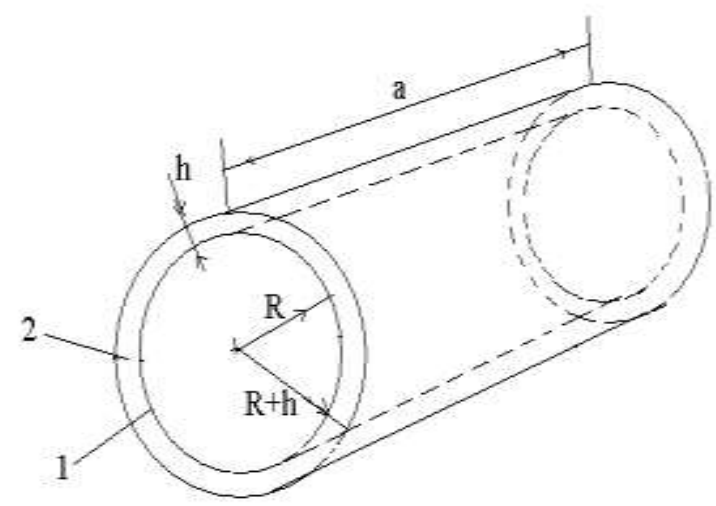

Picture 5 scheme reel-in rolls of libits in a cylindrical shape.

\section{CONCLUSION}

As a result, we'll get avrov fabric libit to weave our national silk "Khon-atlas","Adras", and "Bekasam. In the production of national fabrics the importance of flow flexibility, in providing this packing density of the libite strands on the drum and the effect of size this was determined based on the experiment.

\section{REFERENCES}

1. Regulation of technical process in avrov fabric of national silk. Moscow 1988y. p. 1415

2. Siddikhov P.S. The technology of weaving and equipment. Tashkent 2017y. p. 109

3. Sevostyanov A.G. methods and resources of the mechanic technical process in weaving textile fabrics. Scientific methodical handout. Light industry. 1980 y. p. 26-28

4. Siddikhov P.S. Basic creation of technology and optimization in manufacturing national avrov fabrics. Monograph. Science \& technology. Tashkent 2017y. p. 60-67 